\title{
Epigenetics as a new avenue for the role of inbreeding depression in evolutionary ecology
}

\author{
P-O Cheptou and K Donohue
}

Heredity (2013) 110, 205-206; doi:10.1038/hdy.2012.66; published online 10 October 2012

$\mathrm{B}$ ecause of its impacts on major lifehistory traits (for example, mating system, dispersal, aging), inbreeding depression has been central in evolutionary biology. Inbreeding depression is defined as the reduction in fitness caused by increased homozygosity of individuals due to selffertilization or biparental inbreeding. The current population-genetics theory of inbreeding depression mainly considers it to be the consequence of recessive deleterious alleles arising through mutations, and secondarily as the consequence of overdominant alleles (Charlesworth and Willis 2009).

In a recent paper, Vergeer et al. (2012) have provided intriguing results that may change our understanding of inbreeding depression and challenge the classical theory of how inbreeding depression evolves. Using a concise experimental design comparing the fitness of selfed offspring relative to that of outbred offspring, the authors showed that epigenetic modifications have a major impact on inbreeding depression in the perennial plant Scabiosa columbaria. They first showed that inbred individuals had higher levels of methylation than outbred individuals. Second, although inbreeding depression was high in the species $S$. columbaria, they showed that inbreeding depression was nearly completely removed after chemical demethylation treatments (5-azacytidine) of $S$. columbaria seedlings.

This observation that gene silencing through methylation is more prevalent in selfed offspring is intriguing, as it suggests that underexpression of certain genes can cause fitness reductions, and that underexpression is associated with homozygosity. Thus, dosage regu-

Dr P-O Cheptou is at the UMR 5175 CEFE-Centre d'Ecologie Fonctionnelle et Evolutive (CNRS), France and $\mathrm{K}$ Donohue is at the Department of Biology, Duke University, Durham, NC, USA

E-mail: pierre-olivier.cheptou@cefe.cnrs.fr lation may contribute to inbreeding effects. Such a clear-cut result is new (see however, Biémont, 2010) and, if generalisable, will enhance our understanding of the genetic causes of inbreeding depression and potentially modify our expectations of how it will evolve.

This result provides a mechanistic explanation for environment-dependent inbreeding depression, which has long been documented by empirical studies (for example, Darwin, 1876). Environmental conditions affect the magnitude of inbreeding depression (Armbruster and Reed, 2005), which may change the outcome of selection on traits such as stability of mixed mating system (Cheptou and Mathias, 2001). Until now, there has been little theoretical investigation of the causes of environmentdependent inbreeding depression (however, see Ronce et al., 2009) in the absence of mechanisms to explain it (see Cheptou and Donohue, 2011 for various hypotheses). As methylation is known to be modulated in part by the environment (Bossdorf et al., 2008), the result of Vergeer et al. (2012) provides a convincing mechanism for such common observations. Specifically, changes in gene-expression regulation may contribute to fitness differences between selfed and outcrossed progeny, as the environment modifies gene expression, those fitness differences (that is, inbreeding depression) are also likely to be environment-dependent.

These results of Vergeer et al. (2012) also shed new light on several empirical results that do not fit with classical theory on inbreeding depression. Models that invoke mutation-selection balance suggest that loci responsible for inbreeding depression typically occur at low frequency. In contrast, empirical studies have concluded that loci responsible for inbreeding depression are often at higher frequencies than can be predicted by mutation-selection balance alone (Kelly and Willis, 2001). Clearly, such a genetic architecture of inbreeding depression does not fit with scenarios of unconditionally deleterious alleles. Instead, the degree to which alleles are deleterious may depend on environmental conditions. Regulation of gene expression through methylation provides a plausible explanation for such results. It is worth noting that such epigenetic mechanisms may be relevant not only for the evolution inbreeding depression but also for the maintenance of genetic variation in fitness traits in natural populations (Charlesworth and Willis, 2009).

More fundamentally, these results of Vergeer et al. (2012) may also change our view of the evolutionary consequences of inbreeding depression, typically viewed as a constraint imposed by unavoidable deleterious mutations. It has been established that methylation can be regulated by both genetic and environmental factors. As a consequence, we may speculate that inbreeding depression may evolve as a response to positive selection on alleles regulating genome methylation. Therefore, although inbreeding depression has typically been considered to be a constraint on the evolution of life-history traits such as self-fertilisation (Lande and Schemske, 1985), the result of Vergeer et al. (2012) indicates that inbreeding depression may be evolutionarily labile and may evolve jointly with other life-history traits.

Such co-evolution will fundamentally depart from the classical paradigm of purging dynamics. Importantly, the amplitude of the methylation effect demonstrated by Vergeer et al. (2012) suggests that such epigenetic regulation may have a strong effect. We need to reconcile the low effect of purging as detected in experimental studies (Byers and Waller, 1999) in spite of high variation in inbreeding depression (Winn et al., 2011). What has been considered for several decades 
as a constraint may actually adapt via positive selection, thus challenging the selective role of inbreeding depression in naturally inbreeding populations.

Overall, Vergeer et al. (2012) may have identified a process that could reconcile a variety of results found in ecological studies of inbreeding depression and populationgenetic theory of inbreeding depression. We may expect much progress in evolutionary ecology by envisaging the consequences of the role of epigenetics in inbreeding depression.

Armbruster P, Reed D (2005). Inbreeding depression in benign an stressfull environments. Heredity 95 235-242.

Biémont C (2010). Inbreeding effects in the epigenetic era. Nat Rev Genet 11: 234.
Bossdorf O, Richards CL, Pigliucci M (2008). Epigenetics for ecologists. Ecol Lett 11: 106-115.

Byers DL, Waller DM (1999). Do plant populations purge their genetic load? Effects of population size and mating history on inbreeding depression. Ann Rev Ecol Syst 30: 479-513.

Charlesworth D, Willis JH (2009). Fundamental concepts in genetics: the genetics of inbreeding depression. Nat Rev Genet 10: 783-796.

Cheptou PO, Donohue K (2011). Environment-dependent inbreeding depression: its ecological and evolutionary significance. New Phytol 189: 395-407.

Cheptou PO, Mathias A (2001). Can varying inbreeding depression select for intermediairy selfing rates? Am Nat 157: 361-373.

Darwin CR (1876). The effects of cross and self fertilization in the vegetable kingdom. Murray: London.

Kelly JK, Willis JH (2001). Deleterious mutations and genetic variation for flower size in Mimulus guttatus. Evolution 55: 937-942.

Lande R, Schemske DW (1985). The evolution of selffertilization and inbreeding depression in plants.1. Genetic models. Evolution 39:1 24-40.
Ronce O, Shaw FH, Rousset F, Shaw RG (2009). Is inbreeding depression lower in maladapted populations? A quantitative genetics model. Evolution 63: 1807-1819. Vergeer P, Wagemaker N, Ouborg NJ (2012). Evidence for an epigenetic role in inbreeding depression. Biol Lett 8 : 798-801.

Winn AA, Elle E, Kalisz S, Cheptou PO, Eckert CG, Goodwillie C et al. (2011). Analysis of inbreeding depression in mixed-mating plants provides evidence for selective interference and stable mixed mating. Evolution 65: 3339-3359.

\section{Editor's suggested reading:}

Bollati V, Baccarelli A (2010). Environmental epigenetics. Heredity 105: 105-112.

Costa e Silva J, Hardner C, Tilyard P, Potts BM (2011). The effects of age and environment on the expression of inbreeding depression in Eucalyptus globulus. Heredity 107: 50-60.

Roze D (2012). Spatial heterogeneity in the strength of selection against deleterious alleles and the mutation load. Heredity 109: 137-145. 